
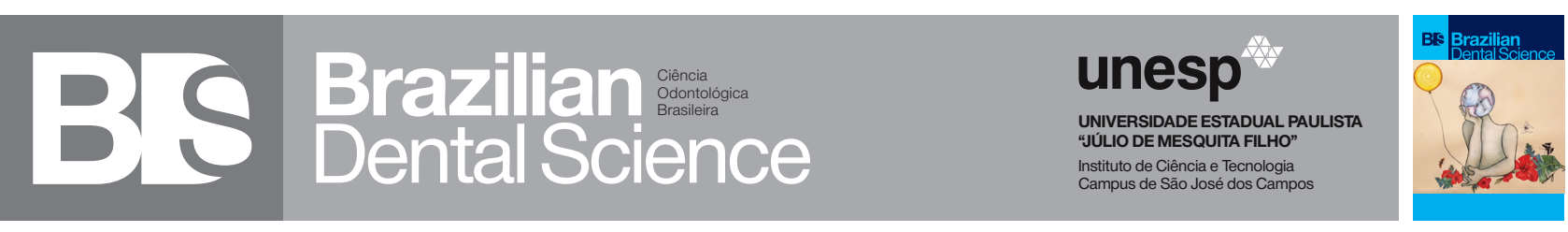

\title{
The finish line location of the cemented crown is an influencing factor for tensile bond strength, marginal adaption and nanoleakage?
}

\author{
A localização do término marginal em coroas cimentadas é um fator que influencia a resistência à tração, adaptação \\ marginal e nanoinfiltração?
}

Enrico ANGELO ${ }^{1}$, Rodrigo Barros Esteves LINS ${ }^{1}$, Luís Roberto Marcondes MARTINS ${ }^{1}$

1 - Piracicaba Dental School - Department of Restorative Dentistry - University Of Campinas - Piracicaba - SP - Brazil.

\begin{abstract}
Objective: The aim of this study was to evaluate the influence of different crowns finishing line location on the crown tensile bond strength, marginal adaption and nanoleakage. Material and Methods: Sixty healthy third molars were collected. For tensile bond strength, a self-adhesive resin cement was used. For marginal adaption, epoxy resin models were prepared. Prior to tensile bond strength test, images for the epoxy resin models were measured under scanning electron microscopy (SEM). Nanoleakage was measured using same protocol. Failure mode was evaluated through SEM and classified: adhesive failure, cohesive in cement, cohesive in dentin, cohesive in resin composite, cohesive in enamel, and mixed. Statistical analysis was performed using Shapiro-Wilk and Kolmogorov Smirnov normality tests, two-way ANOVA, Bonferroni (posthoc) parametric test, with significance level of $5 \%$ $(\mathrm{P}<.05)$, Spearman correlation test. Results: tensile bond strength was not statistically different between the cemented groups with composite resin and ceramic. Cementation of ceramic was not statistically different between the groups (enamel, $3.28 \mathrm{~Pa}$; dentin, 3.14 Pa; resin, 2.85 Pa). Marginal adaption was statistically different between resin and ceramic; finish line location varied between enamel and resin (175.91 $\mu \mathrm{m}$ vs. $433.58 \mu \mathrm{m})$. Nanoleakage rate was statistically different among all groups, except for resin: with resin (9.49\%) and ceramic $(9.35 \%)$. There was a predominance of adhesive failure in all groups. Conclusion: finish line location can be performed safely in enamel and dentin. Composite resinas substrate present an alternative, but still need to be more studied. Regarding the crown's material, it is possible to perform a satisfatory restoration in both: resin and ceramic. With ceramics presenting better results.
\end{abstract}

\section{KEYWORDS}

Resin composite; Ceramics; Tensile bond strengh; Marginal adaption; Nanoleakage.

\section{RESUMO}

Objetivo: O objetivo deste estudo foi avaliar a influência da localização do término marginal na cimentação de coroas, na resistência à tração, adaptação marginal e nanoinfiltração, de acordo com os fatores: término marginal (dentina, esmalte e resina composta), e material restaurador (resina composta e cerâmica). Material e Métodos: Foram coletados 60 terceiros molares hígidos. Para o teste de resistência à tração, todas as amostras foram praparadas com término em chanfro e um cimento resinoso autoadesivo foi utilizado para a cimentação. Para a avaliação da adaptação marginal, foram confeccionados modelos em resina epóxica da linha de cimentação das amostras, previamente ao teste de tração, e submetidas à avaliação em microscopia eletrônica de varredura (MEV), para obtenção de imagens que posteriormente foram mensuradas. Para a nanoinfiltração, foram confeccionados fragmentos dos substratos e materiais restauradores, que foram cimentados com o mesmo protocolo. As amostras/imagens foram obtidas em MEV e mensurada a área infiltrada. O padrão de fratura foi avaliado através de imagens obtidas no MEV e classificados em: falha adesiva, coesiva em cimento, coesiva em dentina, coesiva em resina composta, coesiva em esmalte e mista. A análise estatística foi realizada utilizando os testes de normalidade Shapiro-Wilk e Kolmogorov Smirnov, ANOVA a dois fatores, teste paramétrico Bonferroni (post-hoc), com nível de significância de 5\% (P <0,05), teste de correlação de Spearman. Resultados: a resistência à tração não foi estatisticamente diferente entre os grupos cimentados com resina composta e cerâmica. A cimentação da cerâmica não foi estatisticamente diferente entre os grupos (esmalte, 3,28 Pa; dentina, 3,14 Pa; resina, 2,85 Pa). A adaptação marginal foi estatisticamente diferente entre resina e cerâmica; a localização da linha de chegada variou entre esmalte e resina $(175,91 \mu \mathrm{m}$ vs. 433,58 $\mu \mathrm{m})$. Para a nanoinfiltração foi estatisticamente diferente entre todos os grupos, exceto a resina: com resina $(9,49 \%)$ e cerâmica $(9,35 \%)$. Houve predomínio de falha adesiva em todos os grupos. Conclusão: a localização da linha de chegada pode ser realizada com segurança no esmalte e dentina. O substrato em resina composta apresenta uma alternativa promissora, mas ainda precisa ser mais estudado. Em relação ao material da coroa, é possível realizar uma restauração satisfatória tanto em resina composta quanto em cerâmica. Sendo a cerâmica, o material que apresentou melhores resultados.

\section{PALAVRAS-CHAVE}

Resina composta; Cerâmica; Tração; Adaptação Marginal; Nanoinfiltração 


\section{INTRODUCTION}

The he bond strength to withstand chewing forces, the marginal adaption, as well as the resistance to infiltration are important factors to achieve success in the cementation of a crown $[1,2]$. The resinous cement maintains constant contact with the oral environment, and consequently undergoes aging over the time; this could result in a compromise of its mechanical characteristics, due to the degradation of the collagen and polymer network at the cementation interface [3]. Such degradation leads to the formation of marginal degradation and, consequently, to larger infiltrations, which result in lower cementation bond strength $[3,4]$.

Rehabilitation of a tooth with extensive loss of dental structure, can be achieved using different techniques according to the choice of material, such as the use of composite resin directly in the mouth, and indirect restorations with composite resin or ceramic crowns made in the laboratory [4].

The material and technique of choice, as well as the location and design of the marginal end of the restoration are important considerations [5]. The literature reports indicated that enamel consistently presented higher bond strength than dentin, due to its mineral content and low water concentration of up to 3\%; whereas. Adhesion to dentin is more difficulty due to its organic and inorganic composition and high-water content of about $20 \%$ [6]. Through the advanced development of composite resin materials, together with the principle of less wear on dental structure [7], there are not many studies in the literature that have focused on the influence of the location of the marginal end and design of the preparation.

With the aim of preservation the dental structure, and increasing aesthetic requirement of patients, metal-free materials are increasingly being used with high clinical success rate [8]. Rehabilitation has increasingly used ceramics alone, with good aesthetic and functional results [9]; for this purpose, there are several types of ceramics, such as zirconia and leucite, of which lithium disilicate ceramics is he most frequently used type [10], which consists of a high number of lithium disilicate crystals interrelated with the glass matrix and shows good results in terms of marginal integrity and mechanical strength [11].
Composite resin is an alternative material to ceramics that presents satisfactory clinical results [12]; however, a study demonstrated some potential problems with composite resin such as marginal cracks, postoperative sensitivity, and fractures [13].

Problems can be generated by technical errors during the cementation process, such as poor marginal adaptation, increased accumulation of plaque, secondary caries' progression, cracks, and decrease in the bond strength [14]. To overcome these limitations, self-adhesive cement was developed to reduce the sensitivity of the technique by reducing the number of involved steps [1]. Resin cements are friable materials; hence it is important to study the bond strength, marginal adaptation, and resistance to infiltration of the finish line of the cemented crown [3].

The aim of this study was to evaluate the influence of different crowns (microhybrid composite resin and lithium disilicate) finishing line location (dentin, enamel, and resin composite) on the crown tensile bond strength, marginal adaption and nanoleakage. The hypothesis of the study consisted that the marginal finish line location and crown material would not influence the crown cementation in terms of the tensile bond strength, marginal adaption, and nanoleakage.

\section{MATERIAL AND METHODS}

This study was approved by the research ethics committee (CAAE66767417.6.0000.5418).

Sixty third molars obtained from human subjects were included. The following factors were evaluated (as described in the flowchart):

1) finish line location for cementation of the crowns: in dentin, enamel, and resin composite; 2) rehabilitation material: crown in composite resin, and ceramic crown of lithium disilicate in the injected system (E.max Press, Ivoclar Vivadent, Schann, Liechtenstein), in a factorial design $(3 \times 2)$ as described: DR: Dentin finish line- Composite resin crown; DC: Dentin finish line- Ceramic crown; ER: Enamel finish line- Composite resin crown; EC: Enamel finish line- Ceramic crown; RR: Composite resin finish line - Composite resin crown; RC: Composite resin finish line - Ceramic crown. 




Figure 1- Flow-chat presenting the study design.

The response variables were tensile bond strength $(\mathrm{n}=10)$; marginal adaption $(\mathrm{n}=10)$; nanoleakage $(\mathrm{n}=10)$

- Specimens preparation

Prior to the inclusion process, the teeth were sectioned up to 2-mm length of the clinical crown (cement-enamel junction) in a cutter. All teeth were morphologically reconstructed with microhybrid composite resin (Filtek Z 250 XT, 3M ESPE, St. Paul, MN, USA), using 37\% phosphoric acid for 30 seconds on enamel, and 15 seconds on dentin, the acid was washed by water irrigation for 30 seconds, and enamel was dried by 30 seconds. Adhesive used as the bonding agent (Adpter Single Bond 2, 3M ESPE, St. Paul, MN, USA) was applied twice for 20 seconds with air evaporation of the solvent between each application, and subsequently photopolymerized by 20 seconds (Valo, Ultradent-Products Inc., South Jordan, UT, USA). All the specimens of dentin, enamel, and composite resin were prepared by the same recalibrated operator using a diamond-shaped conical drill bit (2135 KG Sorensen, Sao Paulo, Brazil). The preparation of all specimens was carried out following the same pattern, varying only the location of the marginal finish line. An occlusal reduction of $2 \mathrm{~mm}$ was performed with guideline of the inclination of the cuspid, then sequentially it was performed the preparation the walls with $2 \mathrm{~mm}$ thick and inclination of 5 degrees.

A retention loop was made on the occlusal surface of the resin/ceramic unitary crown. The crown of laboratory-made resin was produced following the same characteristics of the ceramic crown, and then polymerized.

\section{Cementation}

A self-adhesive resin cement (Relyx U 200, 3M ESPE, St. Paul, MN, USA) was used as follows: Composite resin unitary crown: Preapplication of $37 \%$ phosphoric acid for 30 seconds, water irrigation for 30 seconds, and complete drying of the surface were performed. Sequentially, a thin layer of universal single-bond adhesive (3M ESPE, St. Paul, MN, USA), and selfadhesive cement was applied. Ceramic unitary crown: Preapplication of $5 \%$ hydrofluoric acid for 20 seconds, water irrigation for 30 seconds, and complete drying of the surface were performed. Sequentially, a thin layer of universal single-bond adhesive (3M ESPE, St. Paul, MN, USA) and selfadhesive cement was applied. Due to the diffuse orientation of the enamel's prisms, that presents difficulty in terms of etching and penetration the substrate by the self-adhesive cement monomers, it was performed a selective etching on enamel. Enamel finish line: Preapplication of phosphoric acid at $37 \%$ for 30 seconds, water irrigation for 30 seconds, and complete drying of the surface were conducted. Sequentially, the unitary crown was placed with self-adhesive cement, and photopolymerization for 30 seconds was performed. Dentin finish line: Without previous acid etching (following the manufacturer's instructions), water irrigation of the dentin was performed for 30 seconds and only the excess was removed, leaving the dentin wet. Sequentially, the unitary crown was placed with self-adhesive cement, and photopolymerization for 30 seconds was performed. Composite resin finish line: Preapplication of phosphoric acid at $37 \%$ for 30 seconds, water irrigation for 30 seconds each, and complete drying of the surface were performed. 
Sequentially, a thin layer of universal single-bond adhesive (3M ESPE, St. Paul, MN, USA) was applied, the unitary crown was placed with the self-adhesive cement, and photopolymerization for 30 seconds was performed.

The cementation process was done by the same operator who was pre-calibrated. The samples were polymerized for 30 seconds. The cementation line was isolated, and self-cured polystyrene resin was handled and poured into the region, with a retaining loop made, enabling testing of the system with the universal testing machine.

\section{Tensile Bond Strength}

It was produced along the long axis of the tooth, at a speed of $1 \mathrm{~mm}$ per minute. For the standardization of results, the following equation was used: $R T=F / S . A$. (where: RT, tensile bond strength $(\mathrm{Pa}) ; \mathrm{F}$, force of the cementation line (N); S.A. - sample area, that was checked with a precision digital caliper (Mitutoyo Corporation, Tokyo, Japan).

\section{Failure Mode}

After performing the tensile strength test, the failure mode of the sample was classified by SEM (JEOL JSM-6610LV, MA, US) as: adhesive (cement and substrate), cohesive in cement, cohesive in dentin, cohesive in resin composite, cohesive in enamel, and mixed.

\section{Marginal Adaption}

Before isolating the cementation line in the tensile bond strength test sample, each sample was molded on the palatine and buccal surfaces with silicone material (Express XT, 3M ESPE, , St. Paul, MN, USA) and epoxy resin models from each face (vestibular and palatine) of all specimens were made. Subsequently, all samples were assembled in aluminum stubs to receive a thinlayer coating of gold (Balzers-SCD 050 Sputter Coater, Scotia, NY, USA) and evaluated under SEM (LEO 435 VP, LEO Electron Microscopy Ltd, Cambridge, UK) at magnification of 150X. The images were measured using ImageJ software (LOCI, University of Wisconsin, USA), at three points: both borders and center. Subsequently, the mean of each face was calculated, and in sequence, a new media between the palatine and vestibular face was made to obtain the mean value of the sample.

\section{Nanoleakage}

For the nanoleakage test, the samples of each group were immersed in silver nitrate (manufacturer) solution for 24 hours at $37^{\circ} \mathrm{C}$ in a dark environment. Sequentially, the samples were washed in running water for 2 minutes and immersed in developing solution (manufacturer) for 8 hours under a fluorescent lamp; the samples were washed with distilled water and immersed in polystyrene resin.

After inclusion, the samples were polished with water strips (manufacturer), felt disks and diamond pastes at decreasing granulation (manufacturer). The samples were dried with absorbent paper and treated with phosphoric acid at $85 \%$ (manufacturer) for 10 seconds to achieve demineralization, followed by washing with distilled water. Deproteinization was conducted using a $2 \%$ solution of sodium hypochlorite for 10 minutes; the samples were washed with distilled water and dried at room temperature. Subsequently, the samples were dehydrated in ethyl alcohol (manufacturer) at increasing concentrations for 10 minutes per concentration.

Images on SEM were recorded for evaluation of the infiltrated area using Image J software. For each sample, the total area and infiltrated area was calculated, and the percent infiltration was derived.

\section{Statistical Analysis}

All data were submitted to analysis of normality and homogeneity of values. The statistical analysis performed for all methodologies (bond strength, marginal adaptation and nanoleakage) was two-way ANOVA test with Bonferroni post-hoc test, taking into consideration two variables simultaneously: restorative material (composite resinor ceramic) and finish line location (dentin, enamel or resin composite). Statistical analysis was performed using Shapiro-Wilk and Kolmogorov Smirnov normality test, two-way ANOVA and Bonferroni (post-hoc) parametric tests, with 5\% of significance $(\mathrm{P}<.05)$, and Spearman test of correlation SPSS 21.0 (IBM SPSS Statistic for Windows, v. 21.0, IBM Corp., Armonk, NY, USA). 


\section{RESULTS}

The tensile bond strength (Table I) results was not statistically different between the groups of ceramic and composite resin crown $(\mathrm{P}<0.05)$; the ceramic crown cementation was statistically different between the groups with enamel/dentin (EC and DC) finish line.

Table I - Averages and standard deviation of the tensile bond strength

\begin{tabular}{|c|cc|}
\hline Tensile bond strength $(\mathrm{Pa})$ & Resin composite & Ceramic \\
\hline Dentin & $2.95(0.17)^{\mathrm{Aa}}$ & $3.14(0.35)^{\mathrm{Aab}}$ \\
\hline Enamel & $3.15(0.30)^{\mathrm{Aa}}$ & $3.28(0.45)^{\mathrm{Aa}}$ \\
\hline Resin composite & $2.81(0.47)^{\mathrm{Aa}}$ & $2.85(0.17)^{\mathrm{Ab}}$ \\
\hline
\end{tabular}

Distinctive lowercase letters in a column and uppercase letters in a row represent a significant difference $(p<0.05)$.

The marginal adaption results (Table II) was statistically different between the cemented groups with ceramic and composite resin crown, and those based on finish line location.

Table II - Averages and standard deviation of the marginal adaption

\begin{tabular}{|ccc|}
\hline & $\begin{array}{c}\text { Marginal adaption }(\mu \mathrm{m}) \\
\\
\end{array}$ & \\
\hline Resin composite & Ceramic \\
\hline Dentin & $342.37(21.75)^{\mathrm{Ab}}$ & $291.15(17.56)^{\mathrm{Bb}}$ \\
\hline Enamel & $261.42(8.62)^{\mathrm{AC}}$ & $175.91(7.42)^{\mathrm{BC}}$ \\
\hline Resin composite & $433.58(34.64)^{\mathrm{Aa}}$ & $368.68(30.12)^{\mathrm{Ba}}$ \\
\hline
\end{tabular}

Distinctive lowercase letters in a column and uppercase letters in a row represent a significant difference $(p<0.05)$.

The nanoleakage results (Figure 2) was statistically (Table III) different among all groups, excepting RR and RC.

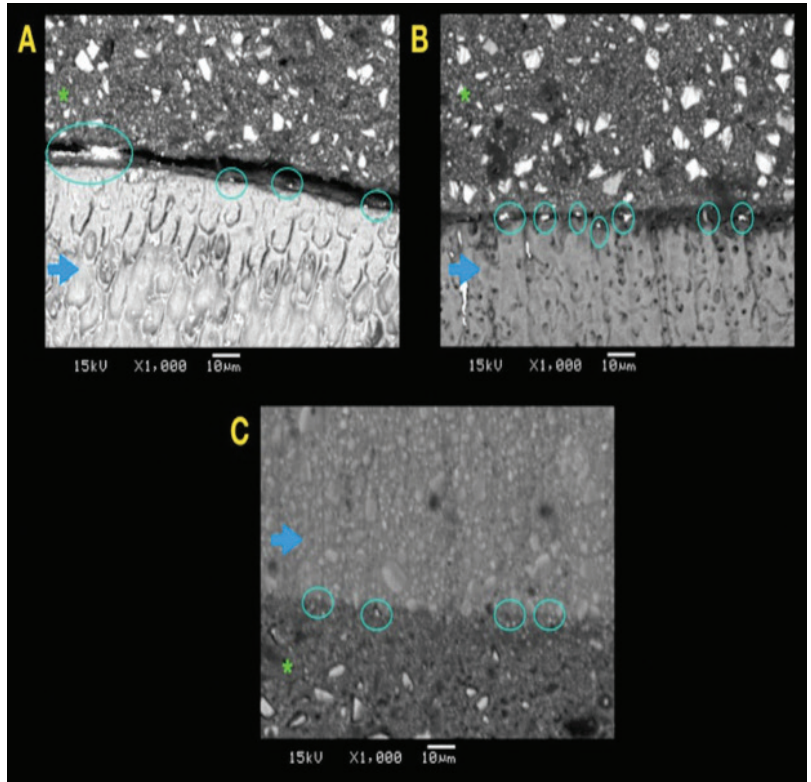

Figure 2 - Nanoleakage. A- Finish line location on enamel. BFinish line location on dentin. C- Finish line location on resin composite. Circles in blue point the observed infiltrations. Asterisks in green point cement layer. Arrows in blue point the finish line location.

Table III - Averages and standard deviation of the nanoleakage

\begin{tabular}{|c|c|c|}
\hline & \multicolumn{2}{|l|}{ Nanoleakage (\%) } \\
\hline & Resin composite & Ceramic \\
\hline Dentin & $23.59(0.65)^{\text {Aa }}$ & $22.14(0.97)^{\mathrm{Ba}}$ \\
\hline Enamel & $15.56(0.44)^{\mathrm{Ab}}$ & $14.66(0.45)^{\mathrm{Bb}}$ \\
\hline Resin composite & $9.49(0.55)^{A c}$ & $9.35(0.18)^{A c}$ \\
\hline
\end{tabular}

Based on the results of failure mode analysis, there were three types of fractures: adhesive, cohesive in resin, and mixed (Figures $3 A-3 D)$. 


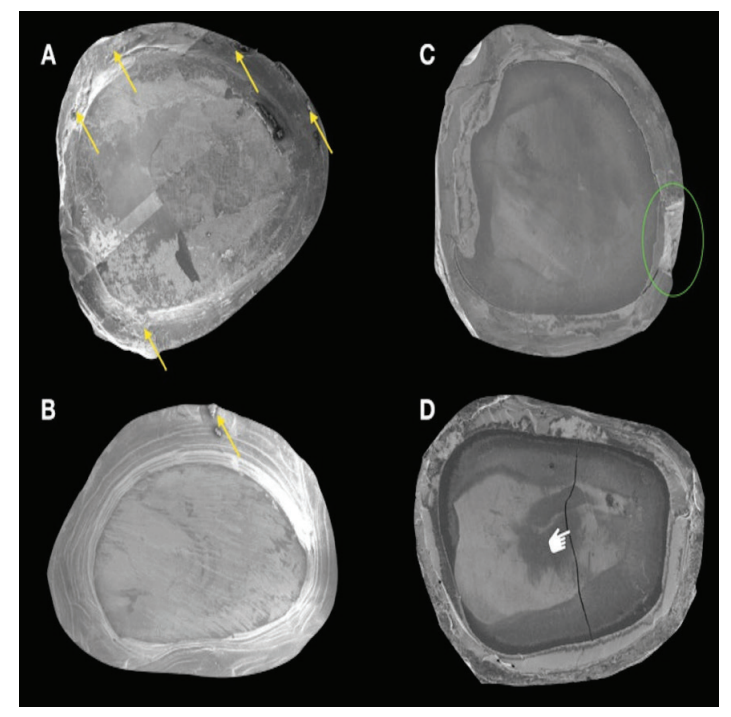

Figure $\mathbf{3}$ - Representative images of different types of failure mode. A and B- Adhesive failure. C- Cohesive in resin; D- Mixed. Arrow pointing the cement present; green circle pointing the cohesive fracture and hand pointing a tooth fracture.

The DR group had a high rate of adhesive failure alone, and the DC group had a high rate of adhesive failure and low percentage of mixed failure cases. The ER and EC groups had a higher rate of adhesive failure followed by mixed failure compared to those of the other groups. The RR group had both adhesive failure and cohesive in resin, whereas, the RC group had a greater percentage of adhesive failure, and lower percentage of cohesive in resin and mixed, as can be observed on Figure 4.

Failure Mode

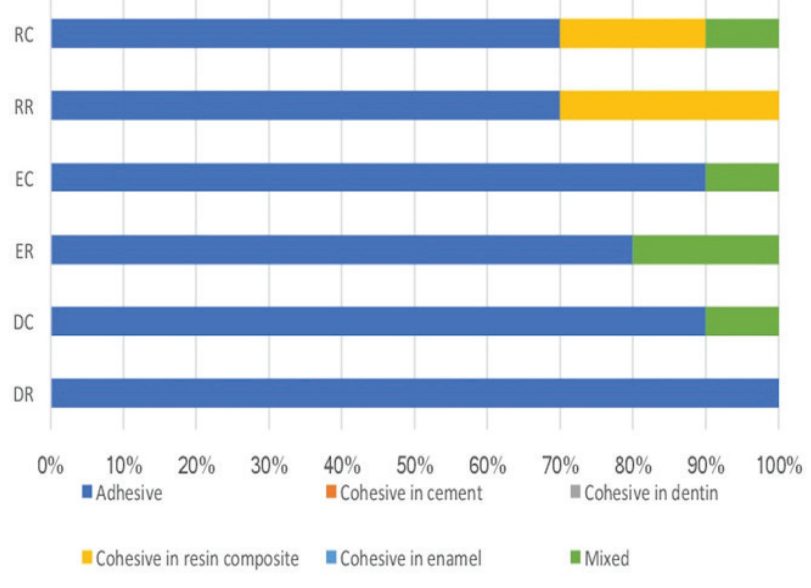

Figure 4 - Percentage of failure mode observed on groups.

\section{DISCUSSION}

The results revealed the presence of group-wise differences indicating that the location of the marginal finish line and material of the crown influenced the tensile bond strength, marginal adaption, and nanoleakage; therefore, our hypothesis was rejected.

The results of the tensile bond strength test indicated that the groups with enamel finish line had better performance, followed in order by those with dentin and resin composite. This phenomenon may be related to the hybridization process involving a network of cross-links [copolymerization] between monomers and those with the hydroxyapatite within the dental structure [8].

The self-adhesive cements comprise acid monomers, such as carboxylic acid and hydroxyethyl methacrylate (HEMA), which create micromechanical retentions through partial etching of the smear layer surface [15]. In addition, there are other monomers, such as phosphate ester, that mediate chemical bonding with the hydroxyapatite, which remains in the dental tissue [6]. Therefore, the bonding process of these materials is more chemical than mechanical [16]. Due to the effect of partial etching and higher viscosity presented by the self-adhesive cement than conventional cements, it is more difficult to the monomers penetration in the tubules; because the material counts in addition to the chemical adhesion with the dental structure, with a mechanical retention with the TAGs, promoting a greater bond strength [15]. However, a report has indicated that the treatment of the enamel's surface with phosphoric acid at $37 \%$ prior to the application of self-adhesive cement increased the strength of adhesion [16]. Since the etching of phosphoric acid in dentin would cause the total removal of the smear layer, which would be something to avoid, since the monomer 10-MDP binds to the dental structure through hydroxyapatite [16]. 
The diffuse orientation of the enamel's prisms presents difficulty in terms of etching and penetration of the substrate for the selfadhesive cement monomers [17]. Surface etching with phosphoric acid at $37 \%$ improves the topography and changes the superficial tension of the surface; therefore, the cement is attracted by capillarity to the pores of the enamel which facilitates mechanical retention in addition to chemical bonding [15]. Moreover, due to the mineral content, the enamel [inorganic component [96\% of weight] comprising calcium phosphate, fluorapatite, carbon apatite; water [3\%]; organic matrix comprising protein matrix [1\%], needs surface etching for adequate adhesion [14]. Results of the tensile bond strength test in this study corroborate with those of previous studies, indicating that the enamel selective conditioning protocol increases the resistance of the adhesive interface for self-adhesive cement with enamel $[15,16]$.

In contrast, the complex composition of dentin [inorganic component comprising intertubular dentin [ $50 \%$ of total composition]; organic matrix comprising collagen, phosphorus, and glycosaminoglycans (30\%); water (20\%) presents an ongoing challenge for the use of self-adhesive cements [6]. The acid monomers of the self-adhesive cement enable etching of the smear layer and produce micro retentions of $2-\square \mathrm{m}$ size $[14,15]$. In addition, removal of the partial smear layer is an advantage, due to the presence of a greater amount of hydroxyapatite in the collagen network, which leads to an increased number of bonds between the monomers, and consequently, an increase in the bond strength of the interface [15].

A study investigating the retention of three different resin cements reported values of 2.9 - 3.9 Pa, similar to those of the tensile bond strength in the present study using similar methodology; the discrepancy between our results and those of other studies could be due to differences in the methodology and composition of materials used [14].
Regarding the marginal adaption, the groups with enamel finish line also presented better performance, followed in order by the dentin and resin composite. The enamel submitted to acid etching undergoes changes in topography which alters the surface tension; consequently, there is better flow of cement through the surface and better seating of the crown [17].

The results showed that the bond strength of the material with dentin presented a worse performance compared to enamel, since the enamel as substrate present a more previsible bond. As previous studies showed that the previous conditioning in dentin did not increase the bond strength in dentin, the protocol used was not to perform the previous conditioning, following the adhesion protocol recommended by the manufacturer. Some reports have indicated that the preapplication of phosphoric acid at 37\% to dentin preceding the application of self-adhesive cement did not improve the mechanical properties, due to the difficulty of the self-adhesive cement of high viscosity to permeate the retentions created in the collagen network [16], which could explain the result in this study of poorer performance of the groups with dentin as finish line location [DR and DC] compared to those of the enamel groups.

It was used resin cement as a simplified adhesive system of self-etching adhesive in a single vial to mediate bonding to the internal surface of the crown, which are both of acidic nature [17]. Due to interaction with oxygen during the cementation process, the acid groups in the unpolymerized layer of the universal single-bond adhesive compete with the peroxides of the cementing agent, for the aromatic tertiary amines, creating an acid-base reaction between the adhesive and cement; this reaction has an effect to decrease copolymerization to below adequate level, resulting in a change in the contraction of the resin cement, and thereby, increased values of the cementation line [18]. In addition, the composite resin finish line is 
without phosphoric acid-mediated surface retentions, and hence, the cement bonding is purely chemical which compromises the seating of the crown [19]; consequently, the marginal adaption for the finish line location of composite resin in the RR and RC groups had the worst performance among all groups.

Internal etching of the crown is another important factor for the success of cementation; for mainly lithium disilicate-based ceramic crowns, application of hydrofluoric acid at 5\% for 20 seconds achieves excellent etching on the inner surface, due to the ratio of crystals in the glassy matrix of this material [20]; whereas, the composite resin crown has the poorer settlement during cementation and lower bond strength than ceramic, due to the lack of free radicals that allow chemical bonding with the cement monomers [21]. These findings corroborate the results in the present study of higher tensile bond strength in all the cemented groups with ceramic crowns than those cemented with composite resin crowns.

The values obtained by the marginal adaption test corroborate those previously reported for resin cements $(180 \mu \mathrm{m}-380 \mu \mathrm{m})$ according to the composition of each material and technique used during cementation [14]; the exception was the group with finish line location and crown in composite resin that showed the highest value indicating the poorest performance and can be explained by the interaction of the self-adhesive cement and self-etching adhesive.

The water content on dentin is necessary factor for the action/bonding process of the self-adhesive cement to release the middle hydrogen ions allowing demineralization of the smear layer by the acid monomers, which can be reused in the reaction between the monomers of phosphate [multifunctional acid] and particles of alkaline charge $[22,23]$. The acidic property of self-adhesive cement due to high concentrations of acid monomers during polymerization is neutralized by reaction between phosphate groups and alkaline charged particles and hydroxyapatite [23]. When neutralization is complete, the cement becomes more hydrophilic, which leads to increased wettability on the surface, and higher susceptibility of the interface to hydrolysis [22]. The action of self-adhesive cement and water concentration of dentin explains the results obtained through the nanoleakage test of poorest performance for the groups with finish line location on dentin [DR and DC] and better performance for the groups with finish line location on enamel [ER and EC] and composite resin[RR and RC], due to their characteristics of lack of water content and absence of water, respectively [22,23].

Previous studies have classified the case of remaining cement in both the tooth and crown as cohesive failure [24], which was observed only in the RR and RC groups of this present study. Adhesive failure was the most frequent failure type in this study, which indicates that the bond strength of the cement to surface is less than that of the cement to crown and the presence of debonding on the surface of the ceramics/composite resinsuch as failure of the bonding crown/cement bond $[23,24]$. This finding may be due to a lack of silane; reports indicate that the acid monomer, present in the universal adhesive, may react with the silane present in the solution, resulting in a volatilization of the same [23-25].

Theself-etching adhesiveused as abonding agent in this study comprises a combination of silane, HEMA, 10-methacryloyloxydecyl dihydrogen phosphate (MDP), and bisphenol-A diglycidyl ether dimethacrylate (Bis-GMA) in a single vial [25]. Adhesives with the MDP component provide a reliable bond between the crown material and tooth surface $[24,25]$. The combination of silane with MDP monomer increases the level of cross-linkages with the methacrylates groups and also improves wettability of the surface, which results in the improved adhesion mechanism of the system [25]. However, studies have indicated the 
absence of significant differences between the use of silane alone and universal single-bond adhesive [25]; moreover, single-vial universal adhesives have problems associated with the instability of silane in solution on contact with MDP and bis-GMA [25]. In acidic media with the presence of water and MDP, the reactions of the silanol group would result in a decreased level of bond strength of the interface and resistance to infiltration $[24,25]$.

Spearman's correlation revealed a negative and high correlation between the tensile bond strength and marginal adaption ( $\mathrm{p}=-0.508 ; \mathrm{P}<.00)$ [26]. The groups with the highest tensile bond strength showed the lowest cementation line [group with enamel finish line location], and those with a higher cementation line showed lower bond strength [group with composite resin finish line location].

Although the enamel groups presented better performance for tensile bond strength and marginal adaption, the composite resin group showed close and satisfactory values. The evaluation of nanoleakage indicated better performance of composite resin versus enamel and dentin due to the difference in water composition of each substrate that has variable effect to lower hydrolysis, and consequently lower infiltration at the interface. This finding suggests higher stability of the interface for composite resin; study including thermomechanical aging of the samples is required to confirm this finding.

The present study highlights that the marginal finish line location has a direct influence on the crucial factors of crown cementation, such as the cement bond strength, marginal adaption, and nanoleakage resistance. The study was conducted using an in vitro model; nevertheless, the findings can be correlated with the clinical behavior of dental materials and structures and enable a guideline for clinicians regarding the location of the marginal finish line for cementation of the crowns.

\section{CONCLUSION}

It can be concluded that the preparation for crown can be performed safely in both enamel and dentin. The composite resin as finish line location presented promising results, however, further studies are still needed to regarding its indication; it may be an alternative to avoid subgingival terms. The restoration can be done safely with crowns made of composite resin or ceramic, ceramic crowns presented better performance, related to bond strength, marginal adaption and nanoleakage.

\section{REFERENCES}

1. Al-Haj Ali SN. In vitro coParison of marginal and internal fit between stainless steel crowns and esthetic crowns of primary molars using different luting cements. DentRes J (Isfahan). 2019 Nov 12;16(6):366-371.

2. Ganapathy D, Sathyamoorthy A, Ranganathan H, Murthykumar K. Effect of Resin Bonded Luting Agents Influencing Marginal Discrepancy in All Ceramic Complete Veneer Crowns. J Clin Diagn Res. 2016 Dec;10(12):ZC67-ZC70. doi: 10.7860/JCDR/2016/21447.9028.

3. Jacobs MS, Windeler AS. An investigation of dental luting cement solubility as a function of the marginal gap. JProsthet Dent. 1991;65:436-42.

4. Pfeifer CS. Polymer-Based Direct Filling Materials. Dent Clin North Am. 2017;61(4):733-750.

5. Cortellini D, Canale A. Bonding lithium disilicate ceramic to feather-edge tooth preparations: a minimally invasive treatment concept. J Adhes Dent. 2012 Feb;14(1):7-10. doi:10.3290/j.jad.a22708.

6. Masarwa N, Mohamed A, Abou-Rabii I, Abu Zaghlan R, Steier L. Longevity of Self-etch Dentin Bonding Adhesives CoPared to Etch-and-rinse Dentin Bonding Adhesives: A Systematic Review. JEvid Based DentPract. 2016 Jun;16(2):96-106. doi:10.1016/j.jebdp.2016.03.003.

7. Minyé HM, Gilbert GH, Litaker MS, Mungia R, MeyerowitzC, Louis DR, Slootsky A, Gordan VV, McCracken MS; National Dental PBRN Collaborative Group. Preparation Techniques Used to Make Single-Unit Crowns: Findings from The National Dental Practice-Based Research Network. J Prosthodont. 2018 Dec;27(9):813-820. doi:101111/jopr.12988. Epub2018 Nov 8.

8. Barizon KT, Bergeron C, Vargas MA, Qian F, Cobb DS, Gratton DG, Geraldeli S. Ceramic materials for porcelain veneers: part II. Effect of material, shade, and thickness on translucency. J Prosthet Dent. 2014 0ct;112(4):864-70. doi: 10.1016/.jprosdent.2014.05.016.

9. Sailer I, Makarov NA, Thoma DS, Zwahlen M, Pjetursson BE. All-ceramic or metal-ceramic tooth-supported fixed dental prostheses (FDPs)? A systematic review of the survival and complication rates. Part I: Single crowns (SCS). Dent Mater.2015 Jun;31(6):603-23. doi:10.1016/j.dental.2015.02.011.

10. Oh SC, Dong JK, Lüthy H, Schärer P. Strength and microstructure of IPS Empress 2 glass- ceramic after different treatments. Int J Prosthodont. 2000 Nov-Dec;13(6):468-72.

11. Sasse M, Krummel A, Klosa K, Kern M. Influence of unitary crown thickness and dental bonding surface on the fracture resistance of full-coverage 
occlusal veneers made from lithium disilicate ceramic. Dent Mater. 2015 Aug;31(8):907-15. doi:10.1016/j.dental.2015.04.017.

12. Gianordoli-Neto R, Padovani GC,Mondelli J, de Lima Navarro MF,Mendonça JS Santiago SL Two-year clinical evaluation of composite resinin posterior teeth: A randomized controlled study. J Conserv Dent. 2016 Jul-Aug;19(4):306-10. doi:10.4103/0972-0707.186446.

13. Ferracane JLComposite resin-State of the art. Dent Mater.2011;27:29-38.

14. Johnson GH, Lepe X,Patterson A, Schäfer O. Simplified cementation of lithium disilicate crowns: Retention with various adhesive resin cement combinations. JProsthetDent. 018 May;119(5):826-832. doi:10.1016/.jprosdent.2017.07.012.

15. Cerqueira LAC, Costa AR, Spohr AM, MiyashitaE, Miranzi BAS, Calabrez Filho S, Correr-Sobrinho L, Borges GA. Effect of Dentin Preparation Mode on the Bond Strength Between Human Dentin and Different Resin Cements. Braz DentJ. 2018 May-Jun;29(3):268-274. doi:10.1590/0103-6440201801809.

16. Radovic I,Monticelli F, GoracciC, Vulicevic ZR, Ferrari M. Self-adhesive resin cements: a literature review. J Adhes Dent. 2008 Aug;10(4):251-8.

17. Rohr N, Fischer J. Tooth surface treatment strategies for adhesive cementation. J Adv Prosthodont. 2017 Apr;9(2):85-92. doi:10.4047/ jap.2017.9.2.85.

18. Manso AP, Silva NR, Bonfante EA, Pegoraro TA, Dias RA, Carvalho RM. Cements and adhesives for all-ceramic unitary crowns. Dent Clin North Am. 2011 Apr;55(2):311-32, ix. doi: 10.1016/j.cden.2011.01.011.

19. Suh BI, Feng L, Pashley DH, Tay FR. Factors contributing to the incoPatibility between simplified-step adhesives and chemically-cured or dual-cured composites. Part III. Effect of acidic resin monomers. J Adhes Dent.2003 Winter;5(4):267-82.
20. VogI V,Hiller KA, Buchalla W, Federlin M, Schmalz G. Controlled, prospective, randomized, clinical split-mouth evaluation of partial ceramic crowns luted with a new, universal adhesive system/resin cement: results after 18 months. Clin Oral Investig 2016;20:2481-92.

21. Kern M, Sasse M, WolfartS. Ten-year outcome of three-unit fixed dental prostheses made from monolithic lithium disilicate ceramic. J Am Dent Assoc. 2012Mar;143(3):234-40.

22. Demir N, Ozturk A, Malkoc M (2014) Evaluation of the marginal fit of full ceramic crowns by the microcomputed tomography (micro-CT) technique. Eur JDent 8:437-444.

23. Kim J, Jeong J, Lee J, Cho H (2016) Fit of lithium disilicate crowns fabricated from conventional and digital impressions assessed with micro-CT.J Prosthet Dent 116:551-557.

24. Moszner N, SalzU,Zimmermann J.Chemical aspects of self-etching enameldentin adhesives: a systematic review. Dent Mater.20050ct,21(10):895-910.

25. Makishi P,André CB, Silva JL, Bacelar-Sá R, Correr-Sobrinho L, Giannini M. Effect of Storage Time on Bond Strength Performance of Multimode Adhesives to Indirect Composite resinand Lithium Disilicate Glass Ceramic Oper Dent. 2016 Sep-0ct;41(5):541-551.

26. Akoglu H. User's guide to correlation coefficients. Turk J Emerg Med. 2018 Aug 7;18(3):91-93. doi:10.1016/j.tjem.2018.08.001.

\section{Enrico Angelo}

\section{(Corresponding address)}

Department of Restorative Dentistry, Piracicaba Dental School, University of Campinas (UNICAMP), Piracicaba, São Paulo, Brazil 